\title{
Prediction of Elite Male Trampolines' Performance Based on the Selected Psychological Capabilities
}

\author{
Sertaç Erciş \\ Correspondence: Sertaç Erciş, Faculty of Sport Sciences, Ataturk University, Erzurum, Turkey.
}

Received: January 25, 2018

doi:10.11114/jets.v6i4a.3210

\author{
Accepted: April 12, $2018 \quad$ Online Published: April 13, 2018 \\ URL: https://doi.org/10.11114/jets.v6i4a.3210
}

\begin{abstract}
Main purpose of this study was prediction of elite male trampolines' performance based on the selected physical and psychological capabilities in different age categories. To this aim, 45 male athletes, athletic experience and competitive experience, who participated in the national trampoline team's preparation camps for participation at the 2014 Asian Games in four age categories included Children (ages 11 and 12 yrs), Juniors (ages 13 and 14 yrs), Adolescents (ages 15 to $17 \mathrm{yrs}$ ), and Seniors (ages $18 \mathrm{yrs}<$ ), were selected using targeted sampling as subjects. Variables of study included 16 variables related to mental skills which were measured using standard procedures and instruments. Data were analyzed using Pearson correlation coefficient and multiple regression models at the 0.05 significance level. Results of study showed that, among all relationships between variables, self-confidence $(r=0.359)$, concentration $(r=0.316)$, concentration recovery $(r=0.394)$, average of psycho-cognitive skills $(r=0.304)$, and total average of mental skills $(r=0.307)$ with performance are statistically significant. Results of regression analysis showed that self-confidence $(\beta$ $=0.522)$ and concentration recovery $(\beta=0.377)$ are significant determinants of performance which explain totally 26.7 percent of the elite male trampolines' competitive performance. Findings of this study suggest that, in the high competitive level of trampoline, psychological factors (i.e., self-confidence and concentration recovery) have more predictive role which must be considered in preparation programs of elite male trampolines.
\end{abstract}

Keywords: psychological fitness, trampoline, elite athlete

\section{Introduction}

In the field of gymnastics, trampolines is as one of the most popular sports fields, is not an exception to these psychological and physical requirements, and the achievement of the championship requires these needs. Recent research results in gymnastics show that, although anthropometric features are important determinants of gymnastic performance, physiological functions play a significant role in this regard (Douda et al., 2008; Nozuhuri, 2016). In general, the owners believe that physiological capabilities alone cannot explain the performance at high levels of heroism, and these features, combined with mental capabilities, can predict the success of the sport (Weiss et al., 1989). Meanwhile, mental skills as inherent or acquired features are among the capabilities that are necessary along with physical and technical capabilities for athletes' achievement. The importance of psychological skills in the performance of athletes of various disciplines, including soccer (Thelwell et al., 2016), basketball (Karamousalidis et al., 2006), Volleyball (Morgan, 2013), Baseball (Smith \& Christensen, 2015), Tennis (Gould et al., 2014), triples (Thelwell \& Greenlees, 2013), Bowling (Paiva, 2011), Cricket (Telwell et al., 2013), and it has been claimed that athletes have high psychological skills at elite levels (Maison, 2012; Wang et al, 2013). Also, the important role of mental skills in the performance of gymnastics has been confirmed in a number of studies (Calmels et al., 2015; Calmels et al. 2013; Fournier et al. 2015; Mahoney \& Avener 2011; Nozuhuri, 2016). Accordingly, in this research, psychological capabilities will be used to explain the performance of elite male tricolor. Nozuhuri (2016) showed that the role of psychological capabilities (self-efficacy and psychological skills) in the performance of elite gymnasts is $36 \%$. Among the psychological skills, the strongest link between mental skills and gymnastics performance has been reported in fear control, concentration and mental exercises respectively, respectively, while resilience and commitment skills had the weakest relationship with the performance of male elite male gymnasts.

Mahoney \& Onner (2007) showed that cognitive strategies such as internal conversation and mental imagery, in comparison with other psychological factors, have a stronger relationship with the performance of male gymnasts. Lee (2008) showed that self-efficacy and performance of female gymnasiums are positive and moderate. Mahoney et al. (2009) showed that concentration, anxiety control, self-esteem, psychological preparation and potential motivation have 
a significant role in differentiating the skill level of elite and non-elite athletes. Orlick \& Partington (2010) found that mental, mental and physical fitness was the only variable that significantly differentiated the Olympic athlete from other athletes. Weiss (2011) showed that self-efficacy is the only significant predictor of gymnastic performance. Kazemi (2012) has shown that gymnasts who have used the combination of physical and mental exercises have had a remarkable improvement over physics-only gymnasts.

Taherkhani (2013) showed that the psychological skills of elite gymnasiums in Iran are higher than average. Mortazavi (2014) showed that the mental skills of both male and female gymnasts are above average and desirable. Nozuhuri (2016) showed that the performance of elite male gymnasiums with a level of self-efficacy, the level of psychological skills is in a meaningful relationship. Now the researcher is going to examine the prediction of the performance of the elite male trampolines based on psychological capabilities.

\section{Materials and Methods}

The present research is considered as a practical one and in terms of the method it is a predictive correlation research.

\subsection{Society, Sample and Sampling Method}

The statistical population of the study was all male trampolines who were invited to gymnastics training camps in 2014 to participate in Asian Games 2014 and participated in competing selections within the campus. These include 48 athletes in six competitive age groups including L5, L6, L7, L8, youth and adults, which included 11, 12, 13, 14, 15-17 and 18 years old.

In a more general division, 48 athletes were invited to the national team camps in four age groups (11 and 12 years old), adolescents (13 and 14 years of age), youth (15-17 years) and adults (18 years) (In each age group 12 people). Due to the limited number of people in the statistical population, non-random sampling method was used. As a result, the research sample was equal to the statistical society. However, 3 people in camps were unable to complete measurements due to injury, which dropped out of the sample and the number of samples dropped to 45. All participants, with full knowledge of the goals and implementation process, participated in this study with full satisfaction.

\subsection{Measuring Tools and Equipment}

In the present study, the following tools and equipment were used to measure the variables of the research:

1- Researcher-made questionnaire for collecting individual information of subjects

2. Digital scales with accuracy of $0.01 \mathrm{~kg}$ equipped with a precision 0.005 meter with SOEHNLE® marking made in Germany to measure the height and weight of subjects

4. The Ottawa Psychosocial Assessment Tool - Third Edition (OMSAT-3) for measuring psychological abilities and psychological readiness of subjects

5. Judging and Arbitration Rules of Gymnastics Federation to assess the performance of the subjects

\section{Measurements}

\section{Personal Information}

Participants' individual information was comprised of eight questionnaires for determining age, competitive age, sporting history, competitive history, membership in the national team, weekly physical and psychological hours, and collecting history records, respectively, using a researcher-made questionnaire.

\section{Psychological capabilities}

Ottawa Mental Skills Assessments Tool (MSAT-3) was used to measure psychological capabilities and psychological readiness of participants. This tool was developed by Durand-Bush et al. (2001), which uses 48 expressions, whose responses to the 5-degree Likert continuum from 1 (totally agree) to 5 (completely disagreeable), 12 skills Measures the mind in the three basic groups. These three groups include:

\section{Group 1: Basic Psychic Skills}

\section{Group 2: Psychosocial skills}

\section{Group 3: Psychological-Cognitive Skills}

The score of each skill is calculated from the mean score of the four related terms. In the present study, the average score of each group of skills was obtained by calculating the mean score of psychological skills related to each group. The internal consistency of the 12 subscales of this questionnaire was based on the data of 335 Canadian athletes from different sports fields between 0. 68 (target) to 0.86 (mental imagery) and Cronbach's alpha for basic mental skills, psychosocial skills And cognitive-psychological skills have been reported 0.88, 0.85 and 0.89 , respectively. Also, the 
reliability of the questionnaire dimensions varied from 0.61 (stress control) to 0.89 (mental imagery) (Durand-Bush et al., 2001). In the present study, the internal consistency of the third version of the Ottawa Psychosocial Assessment Questionnaire (OMSAT-3) was obtained using the Cronbach's alpha coefficient for the whole questionnaire of 0.891.

\section{Competitive performance in the implementation of trampolines}

In order to measure the level of performance of the participants, information about the selection of the camp that was carried out according to the laws of gymnastics federation was used. Based on this intra-camp competition, each participant will execute 20 trampoline motor skills and assess the quality of the performance by five national referees. The range of scores provided by each referee is between 0 and 20 , which is based on the qualitative analysis parameters of skill implementation for each participant. In calculating the performance score, at first, the minimum and maximum grades are eliminated from the five points given for each skill and the average of the three remaining scores is calculated. The final score is calculated from the sum of scores for 20 skills. Participants were also asked to respond to the questions with integrity and precision, given that there was no right or wrong answer in the questionnaires.

\section{Data analysis method}

To describe the data, mean, standard deviation, frequency, frequency, and table and graph drawing were used. In the data analysis, Pearson correlation coefficient was used. All analyzes were performed at $95 \%$ confidence level using Excel software and SPSS version 15.

\section{Results}

Table 1. Descriptive statistics relating to the individual characteristics of the participants Characteristics of statistical indicators

\begin{tabular}{l|l|r|l}
\hline & N & M & SD \\
\hline Age (years) & 45 & 14.17 & 2.86 \\
\hline Sport record (years) & 45 & 7.22 & 3.64 \\
\hline Competition (years) & 45 & 3.31 & 2.44 \\
\hline
\end{tabular}

Individual characteristics in Table 1 show that age, sport history and competitive history of the participants in the study.

Table 2. Distribution of participants based on selected sport variables

\begin{tabular}{l|l|l|r}
\hline Characteristic & subcategory & \multicolumn{2}{|c}{ statistical indices } \\
\hline \multirow{3}{*}{ Competitive age } & & $\mathrm{N}$ & $\%$ \\
\cline { 2 - 4 } & L5 (born in 2001) & 8 & $\% 17.8$ \\
\cline { 2 - 4 } & L6 (born in 2000) & 7 & $\% 15.6$ \\
\cline { 2 - 4 } & L7 (born in 1999) & 8 & $\% 17.8$ \\
\cline { 2 - 4 } & L8 (born in 1998) & 4 & $\% 8.9$ \\
\cline { 2 - 4 } & Youth (born 1996-97) & 6 & $\% 13.3$ \\
\cline { 2 - 4 } & Adults (born in 1995 and below) & 12 & $\% 26.7$ \\
\hline \multirow{5}{*}{ history of membership in the national team } & $\mathrm{Y}$ & 19 & $\% 42.2$ \\
\cline { 2 - 4 } & $\mathrm{N}$ & 26 & $\% 57.8$ \\
\hline
\end{tabular}

Table 2 indicates the age category of competitive groups.

Table 3. Descriptive statistics related to psychological skills

\begin{tabular}{|c|c|c|c|}
\hline \multirow[t]{2}{*}{ Psychic skills } & \multicolumn{3}{|c|}{ Statistical Indices } \\
\hline & $\mathrm{N}$ & $\mathrm{M}$ & SD \\
\hline Average basic psychological skills & 45 & 4.01 & 0.45 \\
\hline Goal setting & 45 & 4.10 & 0.53 \\
\hline Self Confidence & 45 & 4.17 & 0.56 \\
\hline obligation & 45 & 4.03 & 0.59 \\
\hline Moderate mental skills & 45 & 3.43 & 0.47 \\
\hline stress control & 45 & 3.03 & 0.80 \\
\hline Fear control & 45 & 3.41 & 0.73 \\
\hline Resignation & 45 & 3.54 & 0.69 \\
\hline Vigorous & 45 & 3.73 & 0.56 \\
\hline Moderate psychological and cognitive skills & 45 & 3.58 & 0.48 \\
\hline Focus & 45 & 3.46 & 0.74 \\
\hline Recycle the focus & 45 & 3.18 & 0.75 \\
\hline imagination & 45 & 3.92 & 0.72 \\
\hline Mental training & 45 & 3.67 & 0.73 \\
\hline Race Design & 45 & 3.68 & 0.79 \\
\hline Average psychic skills & 45 & 3.66 & 0.41 \\
\hline
\end{tabular}


Table 3 shows that the mean score of psychological skills of elite male trampolines is in psychological skills.

Table 4. Descriptive statistics related to competitive performance

\begin{tabular}{|c|c|c|c|}
\hline \multirow[t]{2}{*}{ Age classes } & \multicolumn{3}{|c|}{ Statistical Indices } \\
\hline & $\mathrm{N}$ & $\mathrm{M}$ & SD \\
\hline L5 & 8 & 216.01 & 53.01 \\
\hline L6 & 7 & 230.71 & 61.61 \\
\hline L7 & 8 & 195.25 & 85.08 \\
\hline L8 & 4 & 267.75 & 17.03 \\
\hline Youth & 6 & 216.03 & 33.05 \\
\hline adults & 12 & 226.66 & 61.09 \\
\hline Total Participants & 45 & 221.85 & 59.89 \\
\hline
\end{tabular}

Table 4 indicates the age category of competitive groups

Table 5. Pearson correlation coefficient for determining the relationship between psychological skills and competitive performance

\begin{tabular}{l|r|r|r}
\hline Predictive variables & $\boldsymbol{N}$ & $\boldsymbol{r}$ & $\boldsymbol{p}$ \\
\hline Average basic psychological skills & 45 & 0.241 & 0.130 \\
\hline Goal setting & 45 & 0.146 & 0.364 \\
\hline Self Confidence & 45 & 0.359 & $0.021^{*}$ \\
\hline obligation & 45 & 0.086 & 0.595 \\
\hline Moderate mental skills & 45 & 0.257 & 0.104 \\
\hline stress control & 45 & 0.213 & 0.182 \\
\hline Fear control & 45 & 0.210 & 0.189 \\
\hline Resignation & 45 & 0.219 & 0.170 \\
\hline Vigorous & 45 & 0.044 & 0.783 \\
\hline Moderate psychological and cognitive & 45 & 0.304 & $0.05^{*}$ \\
skills & 45 & 0.316 & $0.044^{*}$ \\
\hline Focus & 45 & 0.394 & $0.011^{*}$ \\
\hline Recycle the focus & 45 & 0.139 & 0.385 \\
\hline imagination & 45 & 0.076 & 0.639 \\
\hline Mental training & 45 & 0.093 & 0.562 \\
\hline Race Design & 45 & 0.307 & $0.05^{*}$ \\
\hline Average psychic skills & & & \\
\hline
\end{tabular}

The results of Table 5 show that high levels of performance in elite male trampolines are associated with high levels of self-esteem, concentration, rehabilitation, mean score of psycho-cognitive skills, and the average total score of psychological skills. It can be concluded that there is a significant relationship between some psychological skills (especially self-esteem, concentration, re-focus), and the performance of male elite trampolines.

Table 6. Results of regression model of competitive performance level of elite male trampolines

\begin{tabular}{l|l|l|r|r|r|r|r|r|r|r}
\hline $\begin{array}{l}\text { The source of } \\
\text { changing the } \\
\text { variables entered in } \\
\text { the model }\end{array}$ & $\begin{array}{l}\text { The source of changing the } \\
\text { variables entered in the } \\
\text { model }\end{array}$ & $\boldsymbol{d f}$ & $\boldsymbol{R}$ & $\boldsymbol{R}^{2}$ & $\begin{array}{r}\boldsymbol{R}^{2} \\
\text { Modified }\end{array}$ & $\boldsymbol{F}$ & $\boldsymbol{p}$ & $\boldsymbol{\Delta \boldsymbol { R } ^ { 2 }}$ & $\begin{array}{r}\boldsymbol{\Delta} \boldsymbol{P} \\
\boldsymbol{F}\end{array}$ & $\begin{array}{l}\text { For } \\
\text { changes }\end{array}$ \\
\hline & $\begin{array}{l}\text { Mental skills } \\
\text { 2.Re-focus }\end{array}$ & 3 & 0.516 & 0.267 & 0.185 & 3.274 & $0.022^{*}$ & 0.267 & 3.274 & $0.022^{*}$ \\
\hline
\end{tabular}

\section{Discussion and Conclusion}

The findings of the present study indicated that the level of mental skills of elite male trampolines is in the optimal level in the psycho-psychological group and in the psycho-psychological and cognitive skills group is moderately to optimal. The level of psychosocial skills observed among elite male trampolines in this study has a similar situation with the athletes of various disciplines studied in single Sanati research in 2016. Manfred Sanati (2016) evaluated psychological skills of athletes of various sports fields at the dawn of Asian games in Doha, which found that the level of psychosocial athlete's level is higher than their other mental skills.

On the other hand, Taherkhani (2013) in gymnasiums in the Super Bowl Championships, Batch One and Batch of Mortazavi (2014) in elite female and male gymnasts (members of the national team and prominent Iranian champions) in the age range 15 to 18 years old, also, Nozuhuri (2016) in elite male gymnasts reported that the level of psychosocial skills of gymnasiums studied was higher than the average, which is consistent with the findings of the present study regarding elite male trampolines. 
On the other hand, the findings of the research on psychological readiness parameters indicated that the average psycho-cognitive and psychological skills of the total psychological skills are related to the level of performance of the trampolines. More specifically, from the psychological skills, the relationship between the performance of elite male tricolorians with self-esteem, concentration and recovery of the concentration was statistically significant.

These findings suggest that having overall moderate psychological skills may be important in improving the level of performance in the trampoline series. In addition, in the present study, high levels of performance were seen in trompolemans who had high self-esteem and the ability to concentrate and recycle high concentrations, and even based on the results of regression analysis, respectively, two psychological capabilities of self-confidence and recycling were prioritized. The most important predictors of competitive performance were elite male trampolines, which shows that 26.77 percent of the variance in the level of competitive performance is predictable based on these two factors. However, the role of psychological capabilities, especially confidence in the performance of the trampoline field, has not been studied in any research.

But the importance of self-confidence and self-confidence in performing sports from both self-confidence and self-efficacy (more specific self-confidence) has been acknowledged in many studies in the field of gymnastics. For example, Nozuhuri (2016), the role of self-efficacy and psychosocial skills in predicting the performance of elite male gymnasts was $21.9 \%$ and $15.3 \%$, respectively. In addition, similar findings were found in other gymnastics studies. According to Weiss et al. (1989), the importance of self-confidence in the implementation of gymnastics is consistent with the findings of the present study.

In addition, a positive relationship between self-esteem and, more specifically, self-efficacy in sport performance with competitive performance in other sports fields such as marathon (Okumaba, 1986), weightlifting (Lerner and Lucky, 1995), the ship (Trichor \& Associates, 1996), Triple (Brooke and Jane, 1996), Bowling (Bois \& Bingham, 1997), Golf (Biochamp \& Associates, 2002), Horseback Riding (Biochamp \& Winton, 2005), Rock Climbing (Lewin et al. , 2008), fencing (Seifi, 2010) and table tennis (Bighi, 2011), as well as sports teams such as Baseball (George 1994), Basketball (Chase, Owing, Lyrej and George, 1994), Football ( Mayers et al., 2004) and Softball (Heppler and Chase, 2008) has been reviewed and approved. On the other hand, the findings of the present study showed that there is a significant relationship between the mean score of mental skills and the performance of male trampolines. The findings of Mahoney and Oner (1977), Spink (1990) and Calves et al. (2003) also support the positive relationship between mental skills and gymnastics performance. In addition, the findings of the present study are in line with the evidence provided by experimental experiments in gymnastics.

In the research of Calmels et al. (1998), Kazemi (1999), Pearce and Barton (1998) and Forneyer et al. (2005), the effectiveness of psychological training in improving gymnastics performance has been reported. In general, a significant part of the research literature on mental health and athletic performance supports the role that psychological skills play in ideal sport performance. However, due to the different nature of sports, the importance of psychological skills may differ from field to discipline, but in general, the importance of athletic psychological capabilities at high competitive levels is not at stake.

In this regard, the present study also showed that psychological factors play a key role in the high levels of elitism, however, in most trampoline training programs, a program designed to improve the athlete's mental skills Elite is not intended to be considered by the players in this field of sport. It is worth noting that similar conditions have been reported for trampolines athletes in other countries. For example, Morse et al. (2009) found that in spite of the psychological skills of Brazilian elite trampolines, Morse and colleagues (2009) found that, despite the increasing duration of psychological training among the elite Brazilian trampolines, the profile of psychological skills of single trampoliners In the dimension of mental imagery, improvement has significantly improved, and the ability of athletes in other skills remains unchanged. The researchers described the lack of organized programs for not improving their mental skills.

\section{References}

Calmels, C., \& Fournier, J. F. (2001). Duration of physical and mental execution of gymnastic routines. The Sport Psychologist, 15, 142-150. https://doi.org/10.1123/tsp.15.2.142

Calmels, C., D'Arripe-Longueville, F., Fournier, J. F., \& Soulard, A. (2003). Competitive strategies among elite female gymnasts: An exploration of the relative influence of psychological skills training and natural learning experiences. International Journal of Sport and Exercise Psychology, 1, 327-352. https://doi.org/10.1080/1612197X.2003.9671724

Douda, H. T., Toubekis, A. G., Avloniti A. A., \& Tokmakidi, S. P. (2008). Physiological and anthropometric determinants of rhythmic gymnastics performance. International Journal of Sport Physiology and Performance, 3, 41-45. https://doi.org/10.1123/ijspp.3.1.41

Fournier, J., Calmels, C., Durand-Bush, N., \& Salmela, J. (2005). Effects of a season-long PST program on gymnastic performance and on psychological skill development. International Journal of Sport and Exercise Psychology, 3, 


\section{9-77. https://doi.org/10.1080/1612197X.2005.9671758}

Gould, D., \& Krane, V. (1992). The arousal-athletic performance relationship: Current status and future directions. In T. Horn (Ed.), Advances in sport psychology (pp. 119-141). Champaign, IL: Human Kinetics.

Mahoney, M. J., \& Avener, M. (1977). Psychology of the elite athlete: An exploratory study. Cognitive Therapy and Research, 1, 135-141. https://doi.org/10.1007/BF01173634

Mahoney, M. J., Gabriel, T. J., \& Perkins, T. S. (1987). Psychological skills and exceptional athletic performance. The Sport Psychologist, 1, 181-199. https://doi.org/10.1123/tsp.1.3.181

Mohammad, K. R. (1378). Investigating the effect of mental exercises on exercise skills of elite gymnasts athletes (youth and adults). Master's Thesis, Tehran University, Faculty of Physical Education and Sport Sciences.

Mortazavi, S. (2014). The Relationship of Individual and Ecological Features with the Skills of the Elite Gymnast of Iran. Master thesis, Islamic Azad University, Central Tehran Branch, Faculty of Physical Education and Sport Sciences.

Nozuhuri, H. (2016). The prediction of elite male gymnasts based on self-efficacy, psychological skills and some anthropometric features. Master's Thesis, Shiraz University.

Orlick, T. (1990). Commitment and excellence. In T. Orlick (Ed.), In Pursuit of Excellence: How to Win in Sport and Life Through Mental Training (pp. 7-14). Champaign, IL: Human Kinetics.

Paiva, M. (2006). An examination of the relationship between mental skills training and bowling performance. Unpublished doctoral dissertation, Capella University.

Seifi, A. (2010). The relationship between psychological, physiological and perceptual-motor variables with the performance of adult elite fencers. Master's thesis, Islamic Azad University, Science and Research Branch. Faculty of Humanities.

Single industry, Shamsi (2006). The validation of the OMSAT-3 questionnaire and the effect of the psychological readiness program on the level of mental skills selected by the athletes participating in the Asian Games in Doha 2006. The Sports Center for Sports of the National Olympic and Paralympic Academy.

TaherKhani, A. (2011). The prediction of elite male gymnasts based on self-efficacy, psychological skills and some anthropometric features. Master's Thesis, Shiraz University

Thelwell, R. C., \& Greenlees, I. A. (2003). Developing competitive endurance performance using mental skills training. The Sport Psychologist, 17(3), 318-337. https://doi.org/10.1123/tsp.17.3.318

Thelwell, R. C., Greenlees, I. A., \& Weston, N. J. V. (2006). Using psychological skills training to develop soccer performance. Journal of Applied Sport Psychology, 18, 254-270. https://doi.org/10.1080/10413200600830323

Vaghefi, A. (2011). The relationship between self-efficacy, skills, abilities and performance of tennis players on the table. Master thesis, Islamic Azad University, Central Tehran Branch, Faculty of Physical Education and Sport Sciences.

Vandorpe, B., Vandendriessche, J., Vaeyens, R., Pion, J., Lefevre, J., Philippaerts, R., \& Lenoir, M. (2011). Factors Discriminating Gymnasts by Competitive Level. Int. J. Sports Med., 32(8), 591-597. https://doi.org/10.1055/s-0031-1275300

Weiss, M. R., Wiese, D. M., \& Klint, K. A. (1989). Head over heels with success: the relationship between self-efficacy and performance in competitive youth gymnastics. Journal of Sport \& Exercise Psychology, 11, 444-451. https://doi.org/10.1123/jsep.11.4.444

\section{Copyrights}

Copyright for this article is retained by the author(s), with first publication rights granted to the journal.

This is an open-access article distributed under the terms and conditions of the Creative Commons Attribution license which permits unrestricted use, distribution, and reproduction in any medium, provided the original work is properly cited. 